\title{
A Case of Cochlear Implantation in a Patient with Superficial Siderosis
}

\author{
Hiroaki Yazama,* Kensaku Hasegawa, $\dagger$ Yasuomi Kunimoto, $₫$ Tasuku Watanabe,* and Kazunori Fujiwara* \\ *Division of Otolaryngology, Head and Neck Surgery, Department of Sensory and Motor Organs, School of Medicine, Faculty of \\ Medicine, Tottori University, Yonago 683-8503, Japan, †Osaka Gyoumeikan Hospital, Osaka 554-0012, Japan, and $¥$ Kunimoto ENT \\ Clinic, Yonago 683-0805, Japan
}

\begin{abstract}
Superficial siderosis is a disease in which iron from hemoglobin is deposited in the central nervous system, resulting in conditions such as progressive sensorineural hearing loss, cerebellar ataxia, dementia, and pyramidal signs. A 30-year-old man with superficial siderosis received a cochlear implant in the left ear, which had shown complete hearing loss. Good auditory responses were obtained at 14 days after implantation. The postoperative average hearing level with the cochlear implant was $56.7 \mathrm{~dB}$ at 3 months and $55.0 \mathrm{~dB}$ at 6 months. However, the patient showed gradual hearing loss, and the dynamic range changed each time the electrode parameters were adjusted. To assess residual hearing ability, single-photon emission computed tomography was performed together with an assessment of electrical auditory brainstem response, which showed a good response and increased blood flow in both the temporal lobes. Based on this result, we asked the patient to continue using the cochlear implant to see whether a perception of speech response would be obtained. However, the patient discontinued using the cochlear implant because he could not hear satisfactorily. Hearing outcomes after cochlear implant surgery for patients with superficial siderosis are not necessarily good. Therefore, the possibility of unsatisfactory results should be fully explained before recommending this surgery to patients.
\end{abstract}

Key words cochlear implant; siderosis; single-photon emission computed tomography

Superficial siderosis (SS) is a disease in which iron from hemoglobin is deposited in the central nervous system because of chronic bleeding into the subarachnoid space, resulting in conditions such as progressive

Corresponding author: Hiroaki Yazama, MD, PhD

h-yazama@tottori-u.ac.jp

Received 2021 March 23

Accepted 2021 April 14

Online published 2021 May 20

Abbreviations: CI, cochlear implant; cu, current unit; eABR, electrical auditory brainstem response; MRI, magnetic resonance imaging; SPECT, single-photon emission computed tomography; SS, superficial siderosis sensorineural hearing loss, cerebellar ataxia, dementia, and pyramidal signs. ${ }^{1,2}$ A cochlear implant (CI) may be indicated when auditory nerve function is maintained, even in patients with severely impaired hearing. However, the outcomes of CI surgery in patients with SS are not necessarily good. ${ }^{3-6}$ Herein, we report the clinical course of a patient with SS who underwent CI surgery.

\section{PATIENT REPORT}

The patient was a 30 -year-old man with right hand dominance. At 15 years of age, he underwent craniotomy for anaplastic astrocytoma of the midbrain. At 20 years of age, he received surgical treatment for a $\mathrm{C} 5 / 6$ cervical fracture sustained in a traffic accident. He had no familial history of hearing impairment.

At around 21 years of age, the patient began experiencing progressive bilateral hearing loss and slight dizziness. He was diagnosed with SS on the basis of magnetic resonance imaging (MRI) performed at the neurosurgery department of our hospital (Fig. 1a). At 25 years of age, he was referred to our department for consultation regarding hearing aids. On initial examination, his average hearing threshold was $58.3 \mathrm{~dB}$ in the right ear and $40.0 \mathrm{~dB}$ in the left ear. The results of a speech discrimination test yielded a value of $65 \%$ in the right ear. Since the patient was expected to benefit from the use of a hearing aid, he began wearing one. However, his hearing threshold gradually worsened, with only right low-tone hearing remaining at 30 years of age. The left ear showed complete hearing loss (Figs. $1 \mathrm{~b}$ and c).

A neurosurgeon determined that the astrocytoma had been stable for a long period and so follow-up would be possible using computed tomography. Therefore, the patient was referred to us for deciding on the indication for CI surgery to improve his quality of life. An examination of both the tympanic membranes revealed nothing noteworthy. Moreover, computed tomography of the temporal bone revealed no morphological abnormalities in the middle ear, cochlea, vestibule, or semicircular canal. The promontory test showed only sensations of pain in both ears. High-order function assessment using the Wechsler Adult Intelligence Scale-III yielded a FullScale Intelligence Quotient of 64 (Verbal Intelligence 
a)

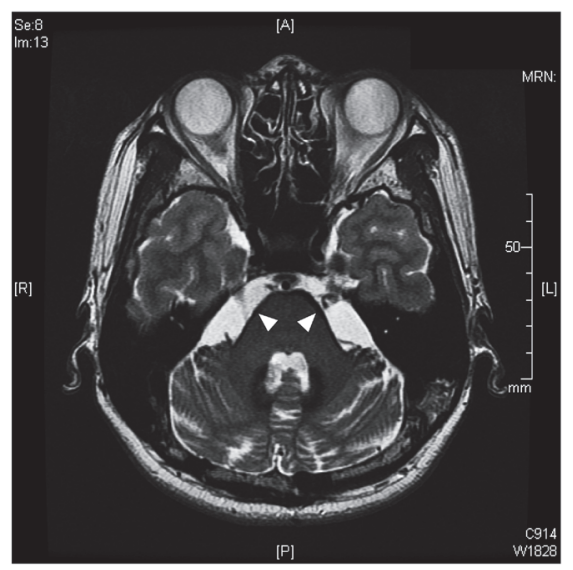

( $\mathrm{Hz})$

C)

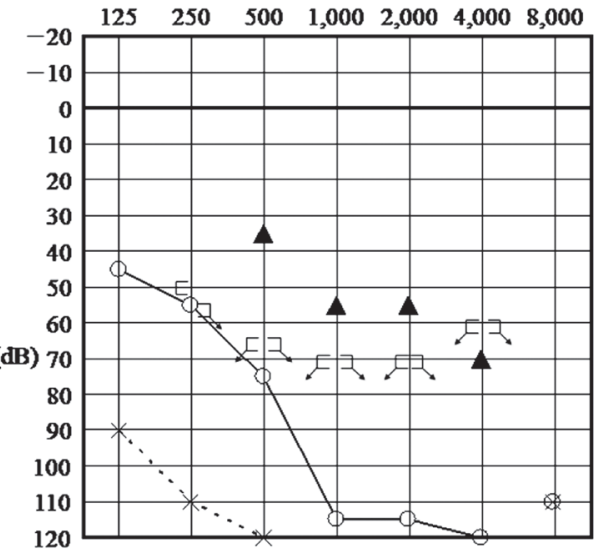

Quotient, 70; Performance Intelligence Quotient, 63).

The patient hoped to reduce the inconveniences caused by hearing impairment. Considering the possibility that the hearing loss might have prevented him from gaining educational benefits and affecting his potential for development, we planned CI surgery. Since he strongly wished to preserve his residual hearing, the left ear was selected for surgery. Using a MED-EL Combi 40+ (MED-EL, Vienna, Austria), CI surgery was performed. All electrodes could be inserted smoothly. The device was activated on postoperative day 7, and the patient experienced some sensation in response to sounds. On postoperative day 14, the sound reaction was fairly good (Fig. 2a). The average efficacy of the CI at 3 months after the CI surgery was $56.7 \mathrm{~dB}$ (Fig. 3a). However, the patient showed gradual hearing loss, and the dynamic range changed each time the electrode parameters were adjusted (Figs. 2b-d). He was dependent on the hearing aid on his right ear for performing the activities of daily living. We observed the patient's course after fixing the electrode parameters and monitored him for any sound response. His average CI efficacy at 6 months after the CI surgery remained
(Hz)

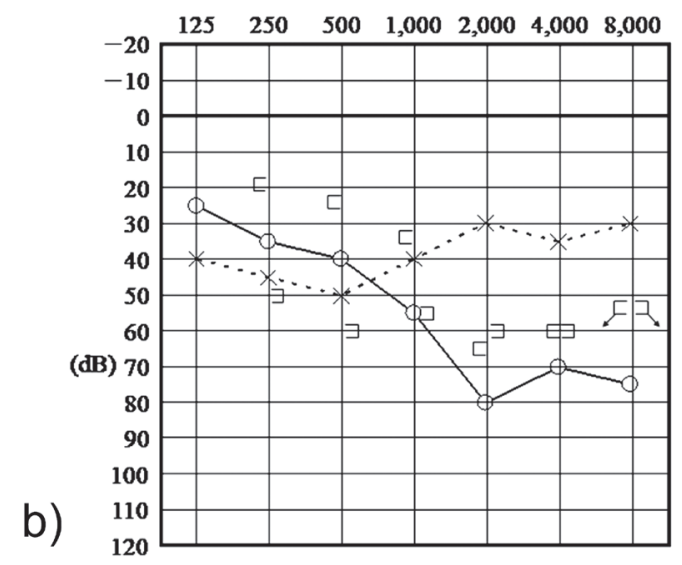

Fig. 1. Preoperative evaluations. a) Findings from head magnetic resonance imaging. Low-intensity changes in the brainstem and on the surface of the cerebellar hemisphere are seen on the T2-weighted image (white arrowheads). b) Audiogram acquired at 25 years of age. Both sides have moderate hearing loss, with the right side showing gradual hearing loss toward high frequency and the left side showing predominantly low-frequency hearing loss. c) Audiogram acquired at 31 years of age. $\boldsymbol{\Delta}$, Hearing threshold when using the right-side hearing aid.

unchanged at $55.0 \mathrm{~dB}$ (Fig. 3b). He was administered a speech perception test (CI-2004), ${ }^{7}$ and word discrimination ability with the CI was $0 \%$. When oral language perception was added to the test battery, the correct response rate was approximately $30 \%$. Therefore, it was unclear whether electrode stimulation was eliciting a sound response by simply asking the patient about his condition.

To objectively assess residual hearing, singlephoton emission computed tomography (SPECT) was performed. A number 12 electrode was used as the stimulating electrode, and it showed good response during map adjustment. After ${ }^{123}$ I-iodoamphetamine was injected, $20 \mathrm{~min}$ of stimulation was performed with a stimulating current of $1,000 \mathrm{cu}$ and a duration of $26.7 \mu$ s. Increased blood flow was observed in both the right and left temporal lobes, and particularly in the left temporal lobe (Fig. 4). This result was attributed to activity in the auditory speech area in the high-tone range, which was affected by the number 12 electrode. We thought that auditory stimulation with the CI would be effective because of residual neural function. Therefore, we asked the patient to continue using the CI to observe 


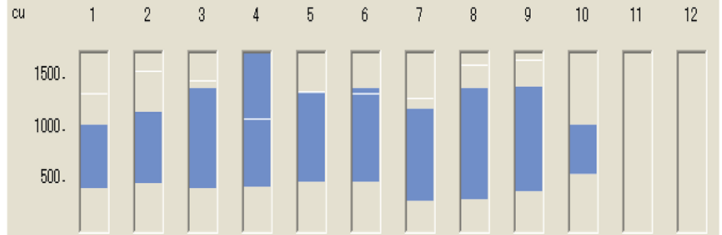

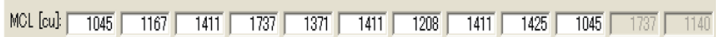

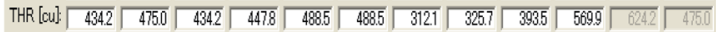

a)

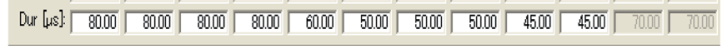

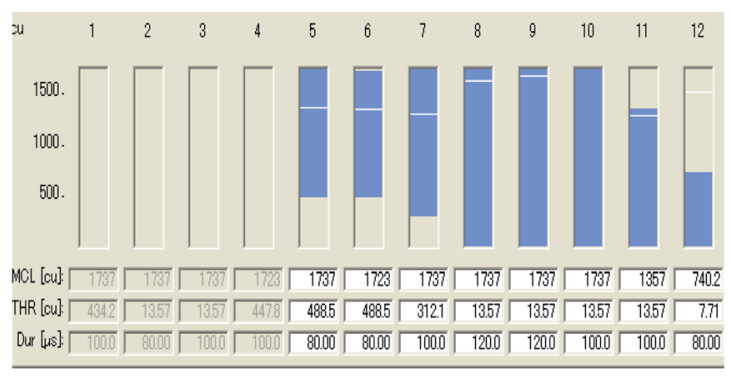

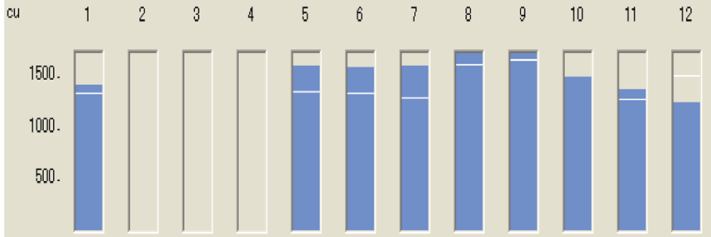

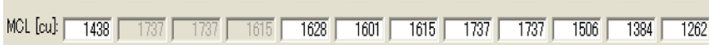

b)

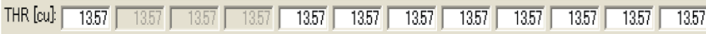

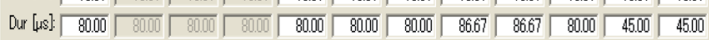

Fig. 2. Postoperative course regarding the electrode fitting parameters. a) The electrode fitting parameters at switch-on. The dynamic range is still narrow and set to a suppressed state stimulus. b) The parameters at 1 month after the surgery. MCL is elevated because of the difficulty in hearing. The low-frequency stimulation is stopped because the patient is dissatisfied with it. The dynamic range is expanded because of the increase in the range of sound perception. c) The parameters at 4 months after the surgery. The high-frequency stimulation is reduced because the patient is dissatisfied with it as well. d) The parameters at 6 months after the surgery (after updating the fitting software). The stimulation in the midrange does not change significantly. MCL, most comfortable level; THR, threshold; Dur, duration.

(Hz)

$\begin{array}{lllllll}125 & 250 & 500 & 1,000 & 2,000 & 4,000 & 8,000\end{array}$

a)

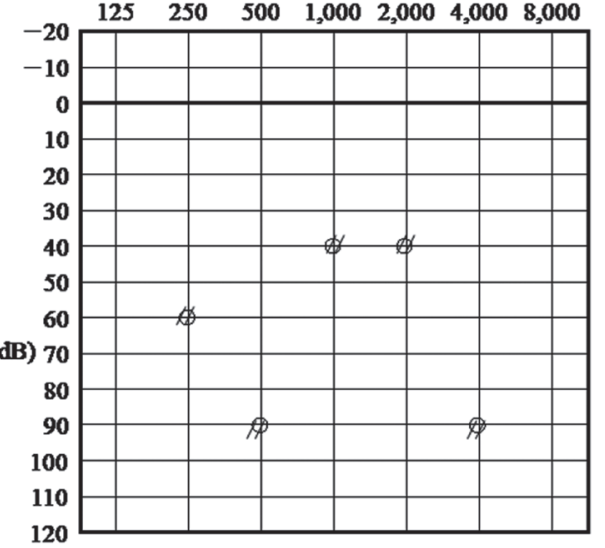

(Hz)

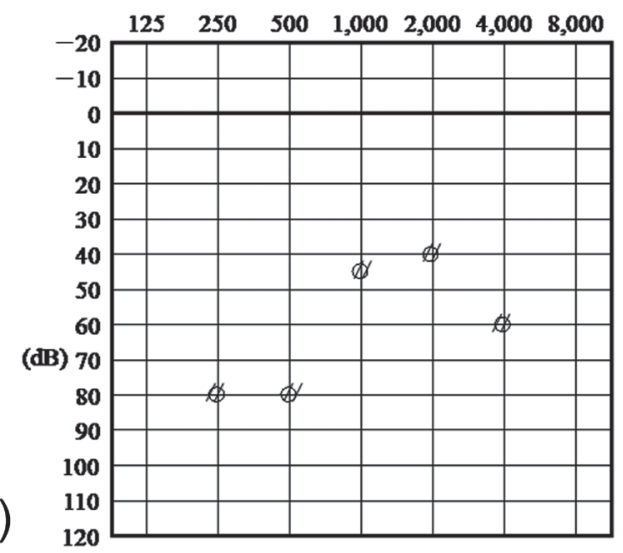

Fig. 3. Audiograms. a) Audiogram acquired at 3 months after the surgery. A response of $40 \mathrm{~dB}$ is found at 1 and $2 \mathrm{kHz}$, which are the frequency bands commonly used in conversations. b) Audiogram acquired at 6 months after the surgery. The hearing thresholds at 1 and $2 \mathrm{kHz}$ are maintained.

whether a perception of speech response would be obtained. However, the patient himself was unmotivated to use the $\mathrm{CI}$ and discontinued using it 2 years after the surgery. One year after he stopped using the implant, he experienced a persistent headache after an epileptic seizure. He was suspected to have recurrent anaplastic 


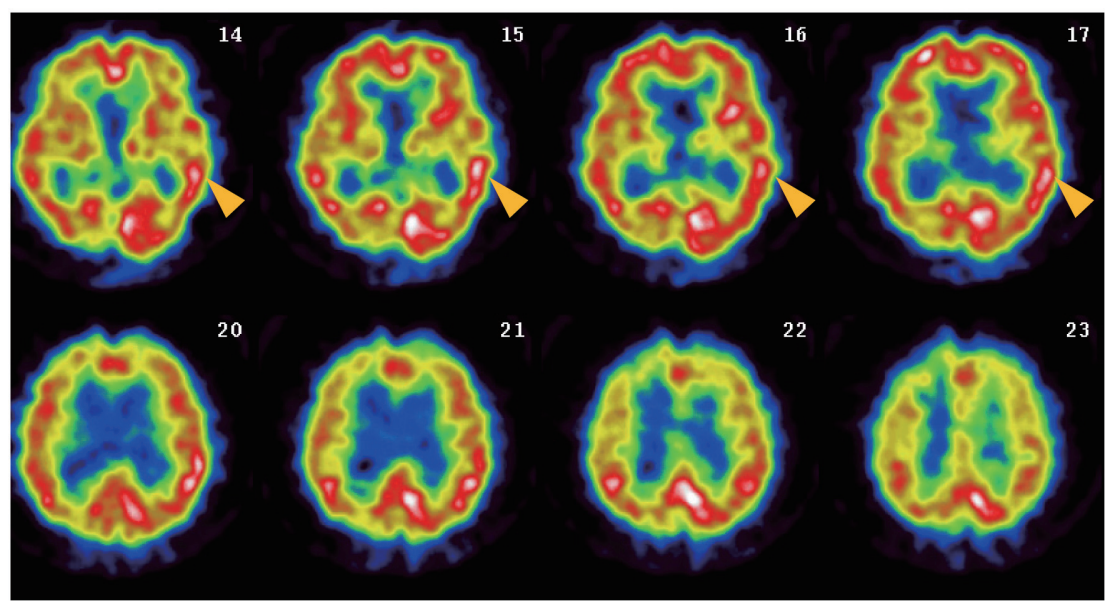

Fig. 4. Single-photon emission computed tomography findings. Increased blood flow is observed in the left and right temporal lobes. In particular, increased blood flow is seen in the left temporal lobe corresponding to Wernicke's area (hot spot shown with arrowheads).

astrocytoma of the midbrain, which necessitated a detailed examination using MRI. Therefore, the implant had to be removed. The removed implant was examined at the MED-EL head office; the examination revealed no implant failure and no problem with the implant that occurred before its removal. The subsequent MRI revealed no recurrence of astrocytoma, and the patient was followed up for epilepsy by a neurosurgeon.

\section{DISCUSSION}

SS is caused by nerve demyelination and degeneration following the deposition of iron from hemoglobin on the eighth cranial nerve, surface of the pons, and surface of the cerebellar hemisphere. It occurs as a result of chronic bleeding into the subarachnoid space following head trauma, intracranial surgery, or other events. However, the cause of bleeding is often unclear, and one study reported that a cause is only discovered in approximately $50 \%$ of cases. ${ }^{8}$ The deposition of iron on the abovementioned areas has been attributed to these sites having a relatively high level of cerebrospinal fluid perfusion and to the fact that the eighth cranial nerve extends over a long course within the cranium. ${ }^{8}$ Hearing loss and ataxia occur when iron is deposited at these sites and the nerves become demyelinated.

On the basis of the results of pure tone audiometry and speech recognition threshold for hearing loss, hearing aids are indicated when they are considered to aid hearing, whereas a CI surgery is indicated when bilateral deafness is present. Table 1 and Table 2 summarize the findings from past reports describing the course of patients more than 3 months after surgery. While good results have been reported in many studies (Table 1), ${ }^{4,-15}$ recent reports indicate that these are not uniformly achieved. ${ }^{3-6}$ The patients whose data are included in Tables were described in a review by Tyler et al., ${ }^{16}$ who concluded that unless symptoms are stable, the benefits of using CIs will probably not be maintained. Six reports have described observations for 2 years or more, but none has provided results after 10 years. Owing to the characteristics of progressive retrocochlear hearing loss in SS, we should await future follow-up investigations of hearing acuity results and symptoms. Among the reports of cases with poor results (Table 2), one patient's perception of repeated sounds gradually decreased several minutes after a powerful sound input in the first week after the device was switched on. Moreover, some patients could not use the CI effectively, and some showed a gradually decreasing efficacy several years after starting to use it, as well as a decrease in the number of electrodes that could be used.

Interestingly, the electrode parameter fluctuations and courses reported in the studies listed in Table 2 resemble those in our case. However, if there is a fluctuation in the effect of the device or if the patient is unable to communicate well because of intellectual disability, output adjustment may not be set properly. Therefore, an objective assessment is needed. The CI electrode itself can measure the state of cochlear stimulation, even though it is not effective in measuring retrocochlear hearing loss. The function of the auditory nerve can be assessed using the electrical auditory brainstem response (eABR), but the activity of the auditory cortex cannot be assessed this way. To assess brain activity, Himi et al. ${ }^{17}$ used auditory stimulation by the CI electrode and assessed brain blood flow changes using SPECT. We adopted this method for a more accurate evaluation and performed a close examination 
Table 1. Patients with good outcomes described in past reports

\begin{tabular}{|c|c|c|c|c|c|c|}
\hline & Patient & Cause & $\begin{array}{l}\text { Disease } \\
\text { duration }\end{array}$ & $\begin{array}{c}\text { Preoperative } \\
\text { assessment }\end{array}$ & $\begin{array}{l}\text { Postoperative } \\
\text { assessment }\end{array}$ & $\begin{array}{c}\text { Observation } \\
\text { duration }\end{array}$ \\
\hline $\begin{array}{l}\text { Irving et al. } \\
(1996)\end{array}$ & $\begin{array}{l}33 \text { y.o. } \\
\text { female }\end{array}$ & Unknown & 3 years & $\begin{array}{l}\text { PT: right sound reaction } \\
\text { ECoG: no reaction } \\
\text { PTA: right } 250 \mathrm{~Hz}, \\
70 \mathrm{~dB} \text { residual }\end{array}$ & $\begin{array}{l}\text { CID sentence score } \\
66 \% \text { (auditory test) }\end{array}$ & 2 years \\
\hline $\begin{array}{l}\text { Hathaway et al. } \\
(2006)\end{array}$ & $\begin{array}{l}44 \text { y.o. } \\
\text { female }\end{array}$ & Head trauma & 5 years & $\begin{array}{c}\text { SRT: } 88 \mathrm{~dB} \\
\text { PT: no reaction }\end{array}$ & $\begin{array}{l}\text { SRT: } 34 \mathrm{~dB} \\
\text { HINT: } 71 \%\end{array}$ & 5 years \\
\hline $\begin{array}{l}\text { Kim et al. } \\
(2006)\end{array}$ & $\begin{array}{l}25 \text { y.o. } \\
\text { male }\end{array}$ & Head trauma & 2 years & ABR: reaction present & $\begin{array}{c}\text { Sentence recognition: } 76 \% \\
\text { Polysyllabic recognition: } \\
50 \%\end{array}$ & 3 months \\
\hline $\begin{array}{l}\text { Joseph et al. } \\
\text { (2011) }\end{array}$ & $\begin{array}{l}57 \text { y.o. } \\
\text { male }\end{array}$ & $\begin{array}{l}\text { After op. } \\
\text { for lumbar disk }\end{array}$ & 4 years & $\begin{array}{c}\text { Right low-tone residual hearing } \\
\text { OAE: no reaction } \\
\text { SRT: } 0 \%\end{array}$ & $\begin{array}{c}\text { CNC: } 28 \% \\
\text { CST sentence score: } 61 \%\end{array}$ & 6 months \\
\hline $\begin{array}{l}\text { Grover et al. } \\
(2011)\end{array}$ & $\begin{array}{l}56 \text { y.o. } \\
\text { female }\end{array}$ & Traffic injury & 25 years & $\begin{array}{l}\text { Left } \leq 2 \mathrm{kHz} \text { residual hearing } \\
\text { BKB: } 22 \% \\
\text { PT: bilateral sound sensation }\end{array}$ & $\begin{array}{l}\text { PTA: } 30-40 \mathrm{~dB} \\
\text { BKB: } 84 \% \\
\text { Open-set: } 0 \%\end{array}$ & 7 years \\
\hline \multirow{2}{*}{$\begin{array}{l}\text { Bitencourt et al. } \\
\text { (2012) }\end{array}$} & $\begin{array}{l}62 \text { y.o. } \\
\text { male }\end{array}$ & Unknown & 5 years & $\begin{array}{c}\text { ABR: S.O. } \\
\text { VR: } 100 \% \\
\text { Closed-set: } 60 \% \\
\text { Open-set: } 0 \%\end{array}$ & $\begin{array}{l}\text { Closed-set: } 100 \% \\
\text { Open-set: } 0 \%\end{array}$ & 3 years \\
\hline & $\begin{array}{l}39 \text { y.o. } \\
\text { male }\end{array}$ & Unknown & $\begin{array}{l}\text { Right: } 2 \text { years } \\
\text { Left: } 12 \text { years }\end{array}$ & $\begin{array}{c}\text { Left } 70 \text { dB residual hearing } \\
\text { ABR: S.O. } \\
\text { VR: } 60 \% \\
\text { Closed-set: } 30 \% \\
\text { Open-set: } 0 \%\end{array}$ & $\begin{array}{l}\text { Closed-set: } 100 \% \\
\text { Open-set: } 70 \%\end{array}$ & 6 months \\
\hline $\begin{array}{l}\text { Nogueira et al. } \\
\text { (2012) }\end{array}$ & $\begin{array}{l}57 \text { y.o. } \\
\text { male }\end{array}$ & Unknown & 35 years & $\begin{array}{c}\text { PTA: right } 110 \mathrm{~dB} \text {, left } 115 \mathrm{~dB} \\
\text { ABR: right S.O., left } 100 \mathrm{~dB} \\
\text { CUNY: } 40 \% \\
\text { BKB: } 5 \%\end{array}$ & $\begin{array}{l}\text { CUNY: } 98 \% \\
\text { BKB: } 86 \%\end{array}$ & 2 years \\
\hline $\begin{array}{l}\text { Sugimoto et al. } \\
\text { (2012) }\end{array}$ & $\begin{array}{l}65 \text { y.o. } \\
\text { female }\end{array}$ & $\begin{array}{l}\text { Subarachnoid } \\
\text { hemorrahage }\end{array}$ & 3 years & $\begin{array}{c}\text { PTA: right S.O., left } 104 \mathrm{~dB} \\
\text { SRT: } 0 \%\end{array}$ & Sentence score: $96 \%$ & 8 months \\
\hline
\end{tabular}

Terminology used in the objective evaluation of hearing threshold: ABR, auditory brainstem response; ECoG, electrocochleography; OAE, otoacoustic emissions; PT, promontory test; PTA, pure tone audiometry. Terminology used in the evaluation of word recognition: BKB, Bamford-Kowal-Bench test; CID, Central Institute for the Deaf Auditory test; CNC, consonant/nucleus/consonant word score; CST, connected speech test; CUNY, City University of New York sentences test; HINT, hearing in noise test; S.O., Scale Out; SRT, speech recognition threshold; VR, vowel recognition; y.o., years old.

of residual auditory function using SPECT with a stimulating current of $1,000 \mathrm{cu}$ and a duration of 26.7 $\mu \mathrm{s}$. Although the stimulation time was $10-20 \mathrm{~min}$ in other reports, we selected a time of $20 \mathrm{~min}$ to ensure sufficient stimulation. The patient was right-handed; hence, the language centers in the left lateral lobe would show significant activity when stimulated. Blood flow was increased in the bilateral temporal lobes, and the increase was greater in the left lateral lobe than in the right lobe. These findings indicated residual function in the language centers. However, language perception could not be acquired by the patient, even with continued CI use. Moreover, the implant was examined by the manufacturer after its removal, even though it showed no defects. The processor had also functioned without any problems; hence, external factors were excluded.

The reason the CI could not be used was that the patient could not hear well enough for his satisfaction. Usually, owing to the plasticity of the brain, speech recognition gradually becomes possible with prolonged use of CIs. However, the lack of understanding of the importance of rehabilitation and difficulty in obtaining the patient's cooperation were other reasons for the lack of continued use of the implant in this case. Therefore, the patient did not experience the benefits of the CI. Surgical decisions for patients who have underlying medical conditions should be made carefully, with full explanation of the fact that the benefits of CIs may not always be achieved. In this case, the electrode had to be removed before the scheduled MRI examination. 
Table 2. Patients with poor outcomes described in past reports

\begin{tabular}{|c|c|c|c|c|c|c|}
\hline & Patient & Cause & $\begin{array}{l}\text { Disease } \\
\text { duration }\end{array}$ & $\begin{array}{l}\text { Preoperative } \\
\text { assessment }\end{array}$ & $\begin{array}{c}\text { Postoperative } \\
\text { assessment }\end{array}$ & $\begin{array}{l}\text { Observation } \\
\text { duration }\end{array}$ \\
\hline $\begin{array}{l}\text { Dooge et al. } \\
(2002)\end{array}$ & $\begin{array}{l}50 \text { y.o. } \\
\text { male }\end{array}$ & $\begin{array}{l}\text { Post brain } \\
\text { tumor } \\
\text { surgery }\end{array}$ & 30 years & $\begin{array}{c}\text { ABR: no reaction } \\
\text { PT: bilateral pain reaction }\end{array}$ & $\begin{array}{l}\text { At early period: HINT AV } 77.3 \% \\
1 \text { year after op: Sound disappeared } \\
\text { with } 1 \text {-min use }\end{array}$ & 9 months \\
\hline $\begin{array}{l}\text { Wood et al. } \\
\text { (2008) }\end{array}$ & $\begin{array}{l}53 \text { y.o. } \\
\text { male }\end{array}$ & Unknown & 5 years & $\begin{array}{l}\text { ABR: no reaction } \\
\text { HINT: AV } 41 \% \text {, AA } 17 \%\end{array}$ & $\begin{array}{l}\text { At early period: HINT AV 25\% } \\
\text { Electrodes that can be used } \\
\text { gradually decreased }\end{array}$ & $\begin{array}{c}1 \text { year } \\
\text { Only ambient } \\
\text { sound } \\
\text { could be heard }\end{array}$ \\
\hline $\begin{array}{l}\text { Yoshikawa et al. } \\
\text { (2009) }\end{array}$ & $\begin{array}{l}54 \text { y.o. } \\
\text { female }\end{array}$ & $\begin{array}{l}\text { Head } \\
\text { trauma }\end{array}$ & 16 years & PTA: bilateral deafness & $\begin{array}{l}\text { At early period: HINT } 71 \% \\
\text { Speech recognition } \\
\text { gradually decreased }\end{array}$ & $\begin{array}{c}8 \text { years } \\
\text { Only } 4 \text { electrodes } \\
\text { could be used }\end{array}$ \\
\hline $\begin{array}{l}\text { Grover et al. } \\
(2011)\end{array}$ & $\begin{array}{l}54 \text { y.o. } \\
\text { female }\end{array}$ & Unknown & 20 years & SRT: $0 \%$ & $\begin{array}{l}\text { Only whistling } \\
\text { rales perceived }\end{array}$ & 9 months \\
\hline
\end{tabular}

Terminology used in the objective evaluation of hearing threshold: ABR, auditory brainstem response; PT, promontory test; PTA, pure tone audiometry. Terminology used in the evaluation of word recognition: AA, no oral form present; AV, oral form present; HINT, hearing in noise test; SRT, speech recognition threshold; y.o., years old.

However, if the patient had been able to continue wearing the device, we should have increased the frequency of use to promote auditory cognition and support him in realizing the benefits of CI use. Therefore, it would have been desirable to increase the frequency of rehabilitation and to support him with closer monitoring during the rehabilitation.

To our knowledge, this is the first study to use SPECT and eABR assessment to evaluate hearing response in a patient with SS, who discontinued the use of the CI because of dissatisfaction with the device. Hearing results after CI surgery for patients with SS are not necessarily always good, and the outcomes of this patient treated in our department were poor. The results of SPECT as an objective assessment confirmed activity in the auditory speech area, even though language perception was not reacquired. When we present the option of CI surgery to patients with SS, the possibility of unsatisfactory results should be fully explained before the surgery.

Acknowledgments: This work was partly supported by Hidenao Miyoshi and Satoshi Nakamatsu (Division of Radiology, Department of Pathophysiological and Therapeutic Science, Faculty of Medicine, Tottori University).

The authors declare no conflict of interest.

\section{REFERENCES}

1 Fearnley JM, Stevens JM, Rudge P. Superficial siderosis of the central nervous system. Brain. 1995;118:1051-66. DOI: 10.1093/brain/118.4.1051, PMID: 7655881

2 Yamana T, Suzuki M, Kitano H. Neuro-otologic findings in a case of superficial siderosis with bilateral hearing impairment. J Otolaryngol. 2001;30:187-9. DOI: 10.2310/7070.2001.20082, PMID: 11771051

3 Dhooge IJM, De Vel E, Urgell H, Gallégo S, Vinck B. Cochlear implantation in a patient with superficial siderosis of the central nervous system. Otol Neurotol. 2002;23:468-72. DOI: 10.1097/00129492-200207000-00013, PMID: 12170147

4 Grover N, Whiteside OJH, Ramsden JD. Cochlear implantation in superficial siderosis - a viable option? Cochlear Implants Int. 2011;12:241-3. DOI: 10.1179/146701011X129500 38111855, PMID: 22251814

5 Wood VH, Bird PA, Giles EC, Baber WJ. Unsuccessful cochlear implantation in two patients with superficial siderosis of the central nervous system. Otol Neurotol. 2008;29:622-5. DOI: 10.1097/MAO.0b013e3181758e7e, PMID: 18665029

6 Yoshikawa N, Hirsch BE. Cochlear implantation in a patient with superficial siderosis: an update. Am J Otolaryngol. 2010;31:390-1. DOI: 10.1016/j.amjoto.2009.05.004, PMID: 20015783

7 Moteki H, Nishio S, Miyagawa M, Tsukada K, Iwasaki $\mathrm{S}$, Usami S. Long-term results of hearing preservation cochlear implant surgery in patients with residual low frequency hearing. Acta Otolaryngol. 2017;137:516-21. DOI: 10.1080/00016489.2016.1252061, PMID: 27852135

8 Revesz T, Earl CJ, Barnard RO. Superficial siderosis of the central nervous system presenting with longstanding deafness. J R Soc Med. 1988;81:479-81. DOI: 10.1177/014107688808100825, PMID: 3418665

9 Bittencourt AG, Goffi-Gomez MVS, Pinna MH, Bento RF, de Brito R, Tsuji RK. Programming peculiarities in two cochlear implant users with superficial siderosis of the central nervous system. Eur Arch Otorhinolaryngol. 2012;269:155563. DOI: 10.1007/s00405-011-1850-1, PMID: 22278194 
10 Hathaway B, Hirsch B, Branstetter B. Successful cochlear implantation in a patient with superficial siderosis. Am J Otolaryngol. 2006;27:255-8. DOI: 10.1016/j.amjoto.2005.09.020, PMID: 16798402

11 Irving RM, Graham JM. Cochlear implantation in superficial siderosis. J Laryngol Otol. 1996;110:1151-3. DOI: 10.1017/ S0022215100135996, PMID: 9015430

12 Kim CS, Song JJ, Park MH, Ho Kim Y, Koo JW. Cochlear implantation in superficial siderosis. Acta Otolaryngol. 2006;126:892-6. DOI: 10.1080/00016480500529330, PMID: 16846938

13 Nadol JB Jr, Adams JC, O’Malley JT. Temporal bone histopathology in a case of sensorineural hearing loss caused by superficial siderosis of the central nervous system and treated by cochlear implantation. Otol Neurotol. 2011;32:748-55. DOI: 10.1097/MAO.0b013e31820e7195, PMID: 21758021
14 Nogueira C, Meehan T. Successful outcome of cochlear implantation in a patient with superficial siderosis. B-ENT. 2012;8:57-9. PMID: 22545393

15 Sugimoto H, Ito M, Hatano M, Yoshizaki T. Cochlear implantation in a patient with superficial siderosis. Auris Nasus Larynx. 2012;39:623-6. DOI: 10.1016/j.anl.2011.10.009, PMID: 22088255

16 Tyler GK, Martin TPC, Baguley DM. Systematic review of outcome of cochlear implantation in superficial siderosis. Otol Neurotol. 2012;33:976-82. DOI: 10.1097/ MAO.0b013e3182565a46, PMID: 22710551

17 Himi T, Shintani T, Yamaguchi T, Nakamura H. Analysis of topographic brain activation using SPECT and statistical parametric mapping in patients with cochlear implant. Igaku No Ayumi. 1999;190:307-8. Japanese. 